\title{
Microstructural evaluation of ball-milled nano Al2O3 particulate-reinforced aluminum matrix composite powders
}

\begin{abstract}
A mechanically alloyed mixture of Al-1 wt.\% nano-alumina (n-Al2O3) composite powders was produced using a planetary ball milling machine. Different milling times were applied to investigate the effect of milling time on the dispersion and microstructure of $\mathrm{n}-\mathrm{Al} 2 \mathrm{O} 3$ particulate reinforcement within the aluminum matrix. A good homogeneous dispersion of nAl2O3 particulates was observed after $8 \mathrm{~h}$ of milling. Longer milling times had no significant effect on the dispersion and morphology of $\mathrm{n}-\mathrm{Al} 2 \mathrm{O} 3$ particulates within the aluminum matrix because a steady state had been reached.
\end{abstract}

Keyword: Composite materials; Microstructure; Ductility; Powder metallurgy 